\title{
Is Deep Brain Stimulation a viable treatment for substance-related addiction?
}

\author{
Giusy Guzzi', Angelo Lavano', Serena Marianna Lavano², Rosa Marotta ${ }^{3}$ \\ ${ }^{1}$ Department of Medical and Surgical Sciences, Neurosurgical Clinic, \\ University "Magna Graecia”, Catanzaro, Italy \\ ${ }^{2}$ Department of Health Sciences, Doctorate Life Sciences, \\ University Magna Graecia, Catanzaro, Italy \\ ${ }^{3}$ Department of Medical and Surgical Sciences, Unit of Child Neuropsychiatry, Pediatric Clinic, \\ University Magna Graecia, Catanzaro, Italy
}

\begin{abstract}
For the ability to modulate the activity of dysregulated networks Deep Brain Stimulation (DBS) of areas involved in reward system and motivational states may have a potential application in addiction despite risks associated with its invasiveness. To date nucleus accumbens core (NAcc) appares to be the most effective target but also anteromedial portion of subthalamic nucleus (STN) and lateral hypothalamus (LH) are studied for clinical purposes. The choice of the target may vary based on the form of addiction: NAcc in alcohol and opiate addiction and STN in cocaine addict patients. Additional studies are still necessary to establish effectiveness and safety of DBS in addiction.
\end{abstract}

Keywords: DBS, addiction, nucleus accumbens, subthalamic nucleus

Deep brain stimulation (DBS) is a neurosurgical intervention first used for treatment of pain, epilepsy and behavioral modifications and afterwards for movement disorders and others neuropsychiatric conditions like OCD, depression and Tourette syndrome $(1,2)$.

The technique uses a implantable device to deliver electrical stimulation in targeted areas of brain circuits to control the dysfunctional neurophysiological signal and improve brain function by local and distant effects. DBS device consists of a battery-powered pulse generator (IPG) implanted subcutaneously in the chest below the clavicle and a quadripolar coiled wire lead, implanted unilaterally or bilaterally with stereotactic technique in the desidered brain area using a skull burr-hole. Although the exact mechanisms of DBS are not fully understood it is a safe and well tollerate therapy with the advantage compared with the advantage compared with ablative procedures to be reversible and adjustable.

Due to application and approval for several neurological disorders, DBS is meanwhile known as a powerful tool to modulate dysregulated networks and has already been considered for substance-related addiction as well (4).

Substance-related addictions therefore constitute the most frequently occurring psychiatric disease category. In addiction to genetic, social and contextual factors underliyng drug addiction there is an alteration of the brain mechanisms that control system of reward or gratification and motivational states, that is the compulsive behaviors associated with the consumption of substances, as well as numerous other functional systems such as those involved in learning and memory (3).

Promising case reports on DBS in addiction in humans have just recently been published $(13,20)$. 
Likewise animal studies, mimicking addiction to several psychotropic substances, point in direction of effectiveness of DBS in substance-related addiction $(15,19)$.

The human use of DBS for the treatment of addiction started from observation in some Parkinson's Disease patients of a phenomenon known as dopamine dysregulation syndrome (DDS), due to a dysfunction of the reward system observed in some individuals taking dopaminergic medications for an extended period of time. It is characterized by self-control problems such as addiction to medication, gambling or sexual behavior. DBS of subthalamic nucleus improved DDS and associated psychiatric symptoms, possibly in relation to reduced misuses and craving for dopamine consumption $(5,6,7,8)$.

Data concerning DBS in substance-related addiction are not only limited but they have also not been shown large impact due to the invasiveness of implanting brain leads. However, it should be noted that the few studies using DBS include very small number of patients with very refractory illness.

Some target areas are proposed for DBS in refractory addiction and the most interesting are nucleus accumbens (NAcc), subthalamic nucleus (STN) and lateral hypothalamus (LH) $(9,10)$. All these targets lie along the circuits of reward and motivation that are involved in development of dependence. A well-documented rationale for the target choice is required in order to investigate the effectiveness, safety and feasibility of the procedure. Since one of the challenge to treat addiction is to diminish the motivation for the drug or object of addiction, without diminishing other forms of motivated behavior, it is important that the targeted structure for a treatment of addiction can dissociate various rewards.

There is considerable preclinical evidence to support a role for NAcc in mediating the motivational effects of conditioned stimuli associated with the drug leading to its anticipation. Findings that DBS of NAcc core decreases motivation for heroin taking and cue-conditioned behaviour and facilitates extinction learning are promising while DBS of NAcc shell seems to have effects only on natural reward decreasing the motivation to food intake. On the basis of this preclinical evidence DBS of NAcc has been proposed in treating behavioral component of addiction disorders and substance abuse in humans. Unfortunately few clinical studies are considering its application and clinical data about its efficacy exist in the literature in small case series, mostly concerned with alcohol and opiate addiction that is in situation where negative reinforcement plays a crucial role $(11,12,13)$.

STN represents another potentially effective target in addiction that can decrease the desire for drugs without influencing other motivated behaviors. Within STN exists a topological specialization in such a way that motivational and emotional contents are related to anteromedial portions (limbic and associative parts) and motor control to its posterolateral portion (sensory-motor part): DBS in limbic and associative parts can have effects on substance-related dependence. However STN DBS may not be appropriate for all forms of addiction and literature data suggest that it may be usefull specially to diminish the desire for cocaine $(14,15,16)$.

LH drive control of food motivated behavior has been extended to drug reward. Electrical stimulation of the posterolateral hypothalamus seems to have similar effects to the hypothalamotomy producing a reduction of cocaine intake but preserving the processes of motivation. Lack of effectiveness on motivation and possible severe adverse effects make posterolateral hypothalamus a target that cannot be used in addiction at the moment (17).

In conclusion, despite no published randomized controlled trial on effect of DBS in patients with addictive behaviours is available, NAcc appears to be a interesting target followed by STN and LH. but additional study are need to establish suitability for clinical purposes. Moreover it is possible that target varies depending on the addiction form the patient suffers from: STN in cocaine addict patients and NAcc in alcohol and opiate addiction.

Choosing invasive procedure for a treatment always raises ethical issues, but for extreme severe treatment-resistant cases or when there is no real efficient treatment as for certain forms of addiction, DBS can be valid therapeutic option. Invasiveness of the method should be kept in mind and clinicians should be particularly vigilant in explaining the risk of DBS to drug dependent patients, who are likely to be much younger than individuals seeking treatment for neurodegenerative diseases. 


\section{REFERENCES}

1. Hariz, MI, Blomstedt P, Zrinzo L. Deep Brain Stimulation between 1947 and 1987: the untold story. Neurosurg Focus 2010 Aug; 29 (2): $E 1$

2. Budman E, Deeb W, Martinez-Ramirez D, Pilittsis JG, Peng-Chen Z, Okun MS, Ramirez-Zamora A. Potential indications for deep brain stimulation in neurological disorders: an evolving flield European Journal of Neuroloy 2018. 25:434-440: E29-E30

3. Koob GF, Volkow ND. Neurobiology of addiction: a neurocircuitry analysis. Lancet Psychiatry 2016 8:760-73.

4. Saleh C, Okun MS. Clinical review of deep brain stimulation and its effects on limbic basal ganglia circuitry. Front Biosci 2008,13:57085731.

5. Knobel D, Aybek S, Pollo C, Vingerhoets FJ, Berney A. Rapid resolution of dopamine dysregulation syndrome (DDS) after subthalamic DBS for Parkinson disease (PD): a case report. Cogn Behav Neurol. 2008; 21:187-189.

6. Lim SY, O'Sullivan SS, Kotschet K, Gallagher DA, Lacey C, Lawrence AD, Lees AJ, O'Sullivan DJ, Peppard RF, Rodrigues JP, Schrag A, Silberstein P, Tisch S, Evans AH, Dopamine dysregulation syndrome, impulse control disorders and punding after deep brain stimulation surgery for Parkinson's disease. J Clin Neurosci 2009, 16:1148-1152.

7. Eusebio A, Witjas T, Cohen J, Fluchere F, Jouve E, Regis J, Azulay JP. Subthalamic nucleus stimulation and compulsive use of dopaminergic medication in Parkinson's disease. J Neurol Neurosurg Psychiatry. 2013

8. Witjas T, Baunez C, Henry JM, Delfini M, Regis J, Cherif AA, Peragut JC, Azulay JP. Addiction in Parkinson's disease: impact of subthalamic nucleus deep brain stimulation. Mov Disord. 2005; 20:10521055.

9. Stelten BM, Noblesse LH, Ackermans L, Temel Y, Visser-Vandewalle V. The neurosurgical treatment of addiction. Neurosurg Focus 2008, 25:E5.

10. Luigjes J, van den Brink W, Feenstra M, van den Munckhof P, Schuurman PR, Schippers R, Mazaheri A, De Vries TJ, Denys D. Deep brain stimulation in addiction: a review of potential brain targets. Mol Psychiatry. 2012 Jun;17(6):572-83
11. Li N, Wang J, Wang XL, Chang CW, Ge SN, Gao L, et al: Nucleus accumbens surgery for addiction. World Neurosurg 2013 80:S28. e9-S28.e19.

12. Kuhn J, Lenartz D, Huff W, Lee S, Koulousakis A, Klosterkoetter J, Sturm V. Remission of alcohol dependency following deep brain stimulation of the nucleus accumbens: valuable therapeutic implications? J Neurol Neurosurg Psychiatry. 2007; 78:1152-1153.

13. Zhou $\mathrm{H}, \mathrm{Xu} \mathrm{J}$, Jiang J. Deep brain stimulation of nucleus accumbens on heroin-seeking behaviors: a case report. Biol Psychiatry 2011 69:e41-e42.

14. Lhommee $E$, Klinger $H$, Thobois $S$, Schmitt E, Ardouin C, Bichon A, Kistner A, Fraix V, Xie J, Aya Kombo M, Chabardes S, Seigneuret E, Benabid AL, Mertens P, Polo G, Carnicella S, Quesada JL, Bosson $\mathrm{JL}$, Broussolle E, Pollak P, Krack P. Subthalamic stimulation in Parkinson's disease: restoring the balance of motivated behaviours. Brain. 2012; 135:1463-1477.

15. Rouaud T, Lardeux S, Panayotis N, Paleressompoulle D, Cador M, Baunez $\mathrm{C}$. Reducing the desire for cocaine with subthalamic nucleus deep brain stimulation. Proc Natl Acad Sci U S A 2010, 107:11961200.

16. Baunez $C$, Dias $C$, Cador M, Amalric M. The subthalamic nucleus exerts opposite control on cocaine and 'natural' rewards. Nat Neurosci. 2005; 8:484-489.

17. Marchant NJ, Hamlin AS, McNally GP. Lateral hypothalamus is required for context-induced reinstatement of extinguished reward seeking. J Neurosci 2009, 29:1331-1342.

18. Muller UJ, Sturm V, Voges J, Heinze HJ, Galanzky I, Heldman M, Scheich H, Bogerts B. Successful treatment of chronic resistant alcoholism by deep brain stimulation of nucleus accumbens: first experience with three cases. Pharmacopsychiatry 2009, 42:288-291

19. Knapp CM, Tozier L, Pak A, Ciraulo DA, Kornetsky C. Deep brain stimulation of the nucleus accumbens reduces ethanol consumption in rats. Pharmacol Biochem Behav 2009, 92:474-479

20. Kuhn J, Muller M, Treppmann JF, Bartsch C, Lenartz D et al. Depp Brain Stimulation of nucleus accumbens and its usefulness in severe opioid addiction. Mol Psychiatry 2014, 19:145 